\title{
The spatio-temporal distribution of Oncomelania hupensis along Yangtze river in Jiangsu Province, China after implementation of a new, integrated schistosomiasis control strategy
}

\author{
Jian He, ${ }^{1,2}$ Wei Li, ${ }^{1,2}$ Robert Bergquist, ${ }^{3}$ Jian-Feng Zhang, ${ }^{1,2}$ Liang Shi, ${ }^{1,2}$ Song Zhao,,2 \\ Feng $\mathbf{W u},{ }^{1,2}$ Kun Yang ${ }^{1,2}$ \\ ${ }^{1}$ Key Laboratory of National Health and Family Planning Commission on Parasitic Disease \\ Control and Prevention-Jiangsu Provincial Key Laboratory on Parasite and Vector Control \\ Technology, Jiangsu Institute of Parasitic Diseases, Wuxi; ${ }^{2}$ Public Health Research Centre, \\ Jiangnan University, Wuxi, China; ${ }^{3}$ Private Researcher, Brastad, Sweden
}

\begin{abstract}
This study concerns an integrated strategy of schistosomiasis control, focusing on the management and elimination of the main transmission cycles and reservoirs along Yangtze river, Jiangsu Province (China), instituted in 2004. Our analysis, including mapping, spatial autocorrelation and spatio-temporal scanning, was implemented between 2001 and 2013 to explore the changes in the distribution of Oncomelania hupensis, the intermediate host of Schistosoma japonicum. Two high-density snail locations in the upper and middle reaches of the river were observed along with one high-risk area due to infected snails in the upper reaches at the beginning of the study period. The number of high-density snail habitats declined sharply after 2004 and infected snails disappeared completely by 2010 . Global spatial
\end{abstract}

Correspondence: Kun Yang, Jiangsu Institute of Parasitic Diseases, Yangxiang 117 Meiyuan, Wuxi, China.

Tel. +86.510.68781027-Fax +86.510.85510263.

E-mail: yangkun@jipd.com

Key words: Oncomelania hupensis; Spatial-temporal analysis; Schistosomiasis; Jiangsu province, China.

Contributions: JH and WLi contributed equally to this study.

Acknowledgements: this project was supported by the National S \& T Major Program (grant no. 2012ZX10004220), Project of Health Department of Jiangsu province (No. RC2011094) and Science Foundation of Jiangsu province (BS2015024).

Received for publication: 9 April 2016.

Revision received: 1 August 2016.

Accepted for publication: 1 August 2016.

() Copyright J. He et al., 2016

Licensee PAGEPress, Italy

Geospatial Health 2016; 11:480

doi:10.4081/gh.2016.480

This article is distributed under the terms of the Creative Commons Attribution Noncommercial License (CC BY-NC 4.0) which permits any noncommercial use, distribution, and reproduction in any medium, provided the original author(s) and source are credited. autocorrelation showed spatial clustering of snails in general, as well as of infected ones when snail densities were relatively high, while local spatial autocorrelation showed the number of specific clusters declining and switching spatially from the upper to the middle reaches of the Yangtze river in Jiangsu Province during the study period. The integrated snail control strategy was found to be effective, but the middle reaches of the river will require continued strong control resources.

\section{Introduction}

Infection by Schistosoma japonicum, the parasitic flatworm that causes human schistosomiasis, is still a significant cause of morbidity in China and even more so in the Philippines (Zhou et al., 2009). The snail Oncomelania hupensis is the only intermediate host of $S$. japonicum in China. From the environmental point of view, the endemic areas fall into three main types: the marshlands and lakes region, the hilly and mountainous region, and the plains with water networks. The development of snails is not only affected by their own growth rhythm (Wilke et al., 2000), but also by the prevailing socio-economic situation as well as by environmental variables, such as hydrological characteristics, vegetation type, weather, elevation, etc. (Yang et al., 2005; Seto et al., 2008; Wu et al., 2008; Zhang et al., 2008; Yang et al., 2011).

Jiangsu Province comprises an area of 102,600 $\mathrm{km}^{2}$ located downstream Yangtze River in the eastern part of China, where the marchlands, plains and hilly areas amount to 69,17 and 14\%, respectively. Historically (in 1949), with close to 2.5 million schistosomiasis patients and $1473 \mathrm{~km}^{2}$ of snail habitats, Jiangsu province ranked fourth for snail-infested areas in the country and was also the most seriously affected province (Hong et al., 2011; Zhou et al., 2007). By 1976, however, the snail habitats had declined to less than $2 \%$ of what they once covered, but after the catastrophic floods of 1998 the schistosomiasis epidemic rebounded and the snail habitats increased significantly (Chen et al., 2002; Yang et al., 2012b). In 2004, a new comprehensive control strategy focusing on the management and elimination of the main transmission cycles and reservoirs was announced by the Ministry of Health of China (Wang et al., 2009; Collins et al., 2012). Based on this adjustment, the Government of Jiangsu province announced new medium- and long-term goals for its schistosomiasis control programme in 2005. The new approach included snail control, chemotherapy of both infected humans and livestock, improved sani- 
tation, health education and targeted interruption of the schistosomiasis transmission cycle through environmental and behavioural modification (Yang et al., 2008; Hong et al., 2011; Liang et al., 2012). After the integrated control strategy had taken hold, the snail habitats started to decline, reaching $28 \mathrm{~km}^{2}$ in 2013 (Lei et al., 2014). To follow up what was happening, we decided to apply spatio-temporal models to study the dynamic change of the snail habitats and evaluate the integrated control strategy in order to provide leads for a scientific basis for both snail and schistosomiasis control.

\section{Materials and Methods}

\section{Study area}

The study was centred on the part of Jiangsu province that is divided into a northern and southern part by the lower reach of Yangtze river. This area covers around 27,000 $\mathrm{km}^{2}$ and includes seven cities (Nanjing, Zhenjiang, Yangzhou, Changzhou, Taizhou and Nantong). All snail habitats along Yangtze River in Jiangsu Province were selected. A digital map was downloaded from the national basic geographic map database of the National Basic Geographic Information Centre in China (http://www.ngcc.cn/). This map included all provincial and county-level administrative boundaries and rivers (Figure 1).

\section{The snail survey database}

Snail surveys were performed annually in March and April based on mechanical sampling using $0.1 \mathrm{~m}^{2}$ frames of iron wire, placed about 10 $\mathrm{m}$ from each other (Agresti, 1991) in the snail habitats marked in Figure 1. All snails within the frame were collected, enumerated, crushed and microscopically examined to find out if they contained any $S$. japonicum sporocysts. The number of survey frames investigated along with the total number of live snails found per frame and the number of infected ones were counted. All areas where live snails were found were defined as snail-infested. The snail density was calculated as the number of snails per frame divided by the total number of frames used for the survey; the corresponding density of infected snails was calculated in the same way.

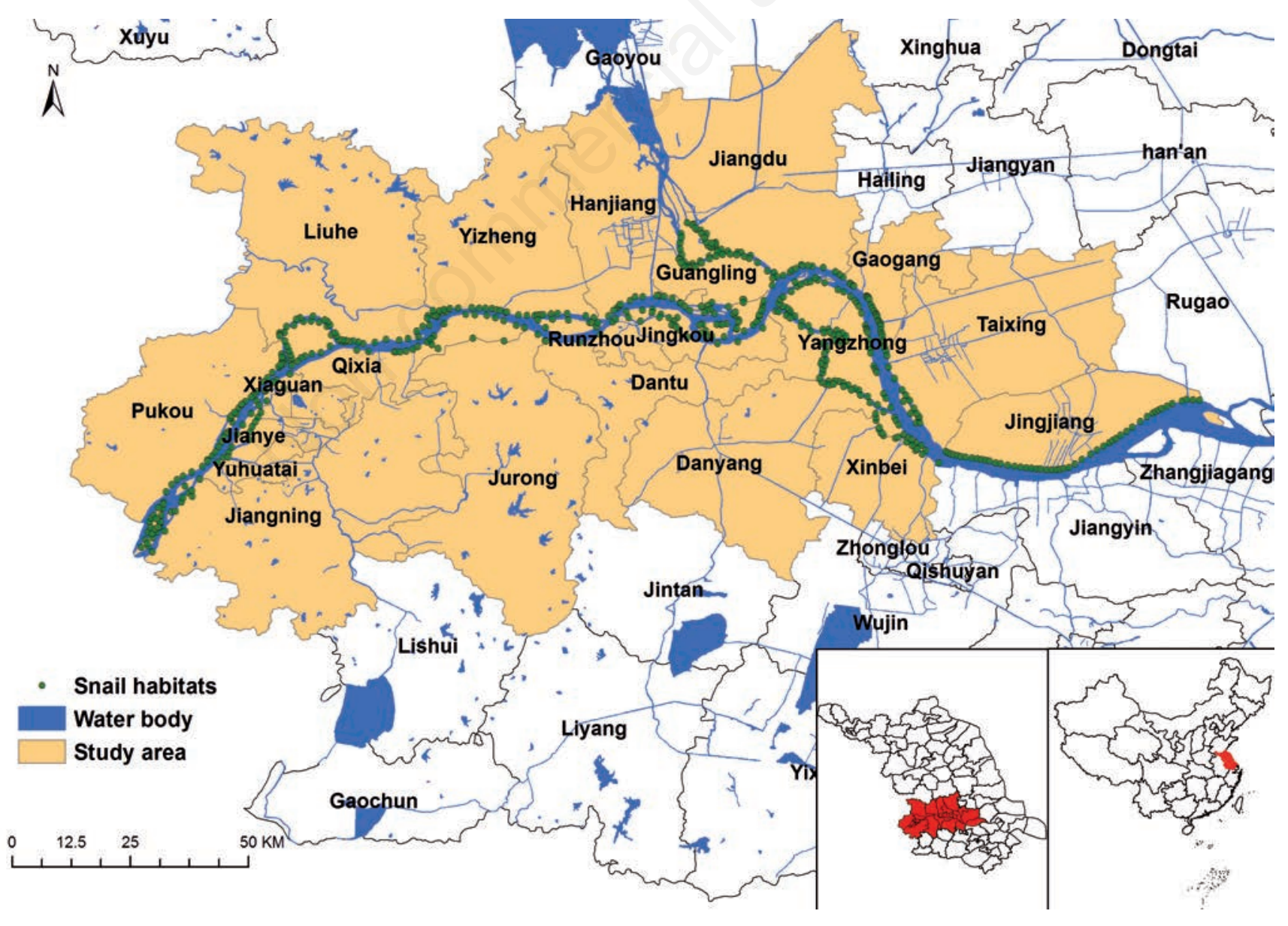

Figure 1. The study region along Yangtze River in Jiangsu Province, China. 


\section{The spatial snail database}

The geographical coordinates of the surveillance sites were recorded with a global positioning systems receiver (Garmin Map76; Garmin, Lenexa, KS, USA). Based on these measurements, we recorded the changes in snail densities and habitats from 2001 to 2013. Then, we plotted the data using Google Earth ${ }^{\circledR}$ (Google, v. 7.1; Google, Mountain View, CA, USA) saving this information as keyhole markup language files (Sun et al., 2011; Yang et al., 2012a). These files were finally transferred into ArcGIS software v. 10.0 (ESRI, Redlands, CA, USA), thereby establishing a spatial survey database.

\section{Descriptive analysis}

The snail data from the different types of snail habitat in Jiangsu Province from 2001 to 2013 were downloaded from the survey database (Table 1). Classification was carried out using Excel (Microsoft Office, v. 2013) comparing the annual changes from 2001 to 2013 with respect to area, snail density and environmental type. The snail density was classified as belonging to one of six levels, namely: $0-0.1 ; 0.1-0.5 ; 0.5-1$; $1-5 ; 5-10$; and $10-\infty$ snails per $0.1 \mathrm{~m}^{2}$ frame. We recorded the total number of live snails and those found to be infected separately.

The chi-square test was used to explore statistically significant differences in snail density and habitat coverage. The linear-by-linear association test by SPSS (IBM, v. 19.0) was used to examine if the ranked data had a linear association (Agresti, 1991; Yaniv et al., 2011). Total snail densities and those of infected snails were mapped in ArcGIS and displayed as circles of different colours and sizes (Figure 2).

\section{Spatial autocorrelation}

Global and local spatial autocorrelation were used to describe the spatial snail distributions at different scales. The former was applied for the spatial distribution at the provincial scale and the latter for the

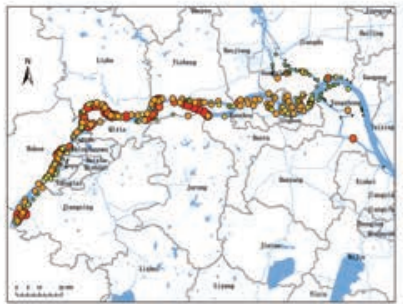

2001

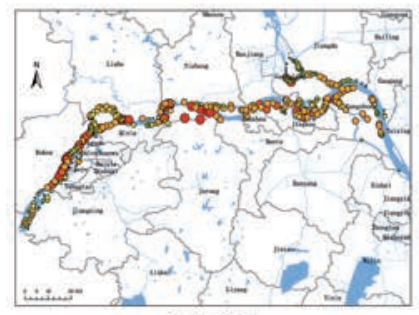

2005

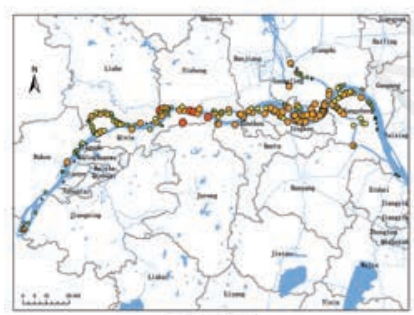

2009

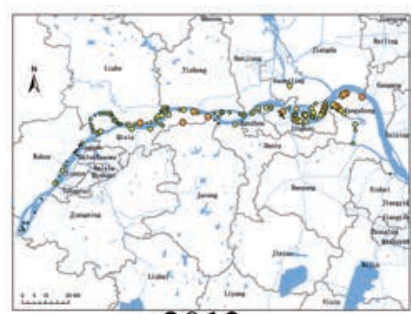

2013

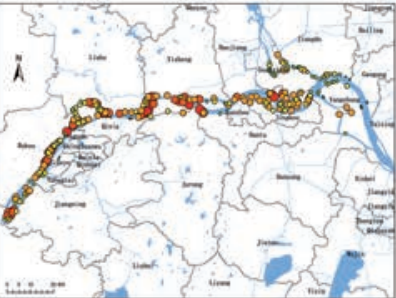

2002

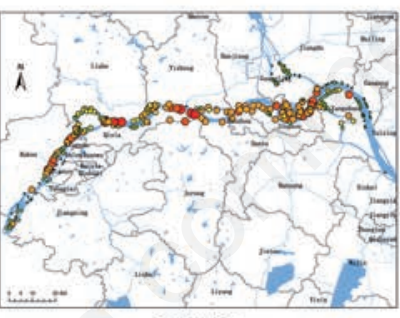

2006

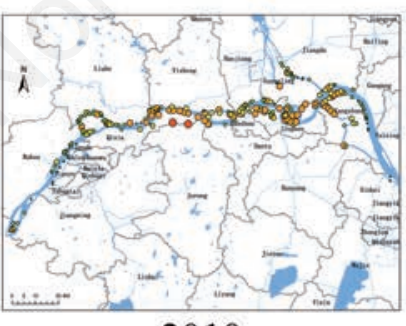

2010

\section{Density}

- $.00-.10$

- $.10-.50$

○ $.50-1.00$

1.00- 5.00

$5.00-10.00$

$10.00-+\infty$

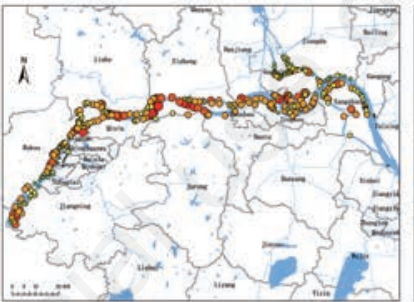

2003

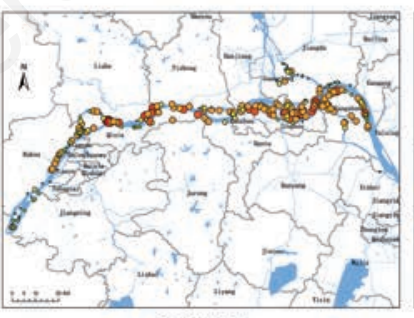

2007

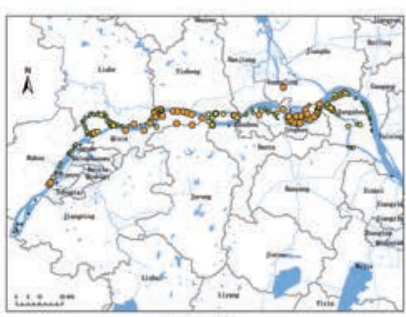

2011

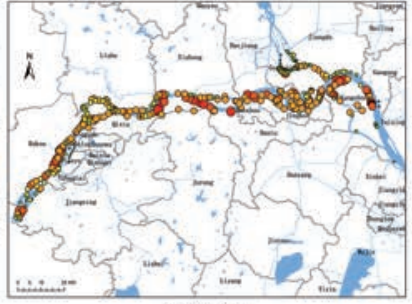

2004

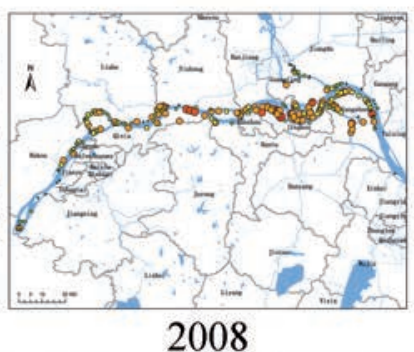

Figure 2. Snail densities along Yangtze River in Jiangsu Province (China), 2001-2013. 
detection of local hotspots and/or coldspots using Gi* index analysis (Ord and Getis, 1995).

Global Moran's $I$ varies between -1 and +1 with positive values indicating positive spatial autocorrelations, negative values negative ones and zero representing a random pattern. This approach was used to detect whether the snail densities (total and infected) had a global spatial autocorrelation at the provincial scale using the formulation:

$I=\frac{n \sum_{i=1}^{n} \sum_{j=1}^{n} w_{i j}\left(x_{i}-\bar{x}\right)\left(x_{j}-\bar{x}\right)}{\sum_{i=1}^{n} \sum_{j=1}^{n} w_{i j} \sum_{i=1}^{n}\left(x_{j}-\bar{x}\right)^{2}}$

where $n$ is the number of spatial units; $x_{i}$ and $x_{j}$ the observed density values $(x)$ in the spatial $i$ and $j$ units; and $W_{i j}$ the weight of the spatial relationship. The $\mathrm{Z}$ test (Ward and Carpenter, 2000) was used to find cluster trends with $\mathrm{Z}>1.96$ indicating such a situation, while $\mathrm{Z}<-1.96$ represents a discrete distribution.

Getis-Ord G statistics (Ord and Getis, 1995) is more sensitive for localised clusters and the $\mathrm{Gi}^{*}$ index is useful for the identification of hotspots or cold spots, i.e. increased or decreased snail densities, since significantly high values are surrounded by other high values and low values are surrounded by low values (Truong and Somenahalli, 2011). The mathematical notations are:

$G_{i}^{*}=\frac{\sum_{j=1}^{n} w_{i j} x_{j}-\bar{X} \sum_{j=1}^{n} w_{i j}}{S \sqrt{\frac{\left[n \sum_{j=1}^{n} w_{i j}^{2}-\left(\sum_{j=1}^{n} w_{i j}\right)^{2}\right]}{n-1}}}$

$\bar{X}=\frac{\sum_{j=1}^{n} x_{j}}{n}$
$\mathrm{S}=\sqrt{\frac{\sum_{j=1}^{n} x_{j}^{2}}{n}-\bar{X}^{2}}$

where $x_{i}$ and $x_{j}$ are the observed snail density values (the $i$ and $j$ spatial total and infected) in units and $W_{i j}$ the weight of the spatial relationship. As for the Moran's I investigation, the Z test was used to detect the significance of the spatial autocorrelation found.

\section{Cluster analysis}

SaTScan $^{\mathrm{TM}}$ (v. 9.4; http://www.satscan.org/) was used to detect clusters of high and low snail numbers by the space-time permutation model, which is defined by a cylindrical window constrained to clusters with both the proportion of the population at risk (for infected snails) and study periods less than 50\% (Coleman et al., 2009). Relative risk (RR), i.e. the estimated risk within the cluster compared to the estimated risk outside the cluster, was calculated for each cluster. The mathematical notation is:

$\mathrm{RR}=\frac{n_{i, r} / \mu_{i, r}}{\left(N-n_{i, r}\right) /\left(N-\mu_{i, r}\right)}$

where $r$ is the radius of observed cases within the cluster; $i$ the code of observed cases; $n_{i, r}$ the observed number of cases within the cluster; $m_{i, r}$ the expected number of observed cases; and $N$ the total number of cases in the dataset. Monte Carlo simulations (999 times) were used for testing the significance at the $0.05 \mathrm{P}$ level.

\section{Results}

Overall, the descriptive statistics demonstrated significant annual improved values after the new strategy had been instituted in 2004, both with respect to snail numbers in general and to those infected.

Table 1. Coverage and proportion of the three types of snail habitats in Jiangsu Province (China), 2001-2013.

\begin{tabular}{lllll} 
Year & Marshlands $\left(\mathrm{km}^{2}, \%\right)$ & Plains and canals $\left(\mathrm{km}^{2}, \%\right)$ & Hills and mountains $\left(\mathrm{km}^{2}, \%\right)$ & Total area $\left.(\mathrm{km})^{2}\right)$ \\
2001 & $63.8-93.4$ & $3.5-5.1$ & $1.0-1.5$ & 68.3 \\
2002 & $67.5-94.1$ & $3.4-4.7$ & $0.9-1.2$ & 71.8 \\
\hline 2003 & $71.0-94.3$ & $3.5-4.6$ & $0.8-1.1$ & 75.3 \\
2004 & $74.0-93.9$ & $4.0-5.1$ & $0.8-1.0$ & 78.8 \\
\hline 2005 & $73.5-93.9$ & $4.2-5.4$ & $0.6-0.8$ & 78.3 \\
2006 & $57.2-93.8$ & $3.4-5.5$ & $0.4-0.7$ & 61.0 \\
\hline 2007 & $44.1-95.7$ & $1.7-3.6$ & $0.3-0.7$ & 46.1 \\
2008 & $38.5-94.5$ & $1.9-4.7$ & $0.4-0.9$ & 40.8 \\
\hline 2009 & $42.2-94.4$ & $2.0-4.5$ & $0.5-1.1$ & 44.7 \\
2010 & $41.7-94.5$ & $2.0-4.4$ & $0.5-1.1$ & 44.2 \\
\hline 2011 & $36.5-94.4$ & $1.8-4.6$ & $0.4-1.0$ & 38.7 \\
2012 & $36.4-94.4$ & $1.8-4.6$ & $0.4-1.0$ & 38.6 \\
\hline 2013 & $26.3-93.8$ & $1.5-5.3$ & $0.3-0.9$ & 28.1 \\
\hline
\end{tabular}


Table 2. The value of Moran's $I$ and its statistical significance of snail habitats along Yangtze river in Jiangsu province (China), $2001-2013$.

\begin{tabular}{|c|c|c|c|c|c|c|}
\hline \multirow[t]{2}{*}{ Year } & \multicolumn{3}{|c|}{ Density of the overall number of snails ${ }^{\circ}$} & \multicolumn{2}{|c|}{ Density of infected snails $\#$} & \multirow[b]{2}{*}{$\mathbf{P}$} \\
\hline & Moran's I & $Z$ & $\mathbf{P}$ & Moran's I & $Z$ & \\
\hline 2001 & 0.22 & 10.52 & 0 & 0.15 & 7.48 & 0 \\
\hline 2002 & 0.27 & 9.53 & 0 & 0.03 & 1.12 & 0.26 \\
\hline 2003 & 0.27 & 15.07 & 0 & 0.15 & 8.45 & 0 \\
\hline 2004 & 0.22 & 13.58 & 0 & 0.12 & 6.72 & 0 \\
\hline 2005 & 0.14 & 8.63 & 0 & 0.18 & 10.01 & 0 \\
\hline 2006 & 0.17 & 8.89 & 0 & 0.13 & 7.11 & 0 \\
\hline 2007 & 0.23 & 6.63 & 0 & 0.10 & 5.15 & 0 \\
\hline 2008 & 0.13 & 3.98 & 0 & 0.03 & 0.83 & 0.41 \\
\hline 2009 & 0.15 & 1.54 & 0.12 & 0.15 & 15.2 & 0.13 \\
\hline 2010 & 0.25 & 2.50 & 0.01 & - & - & - \\
\hline 2011 & 0.30 & 2.24 & 0.02 & - & - & - \\
\hline 2012 & 0.24 & 19.5 & 0.05 & - & - & - \\
\hline 2013 & 0.13 & 0.77 & 0.44 & - & - & - \\
\hline
\end{tabular}

${ }^{\circ}$ Note the absence of clusters in 2009 and 2013 (in italics); ${ }^{\sharp}$ note the absence of clusters in 2002 and $2008-2009$ (in italics).

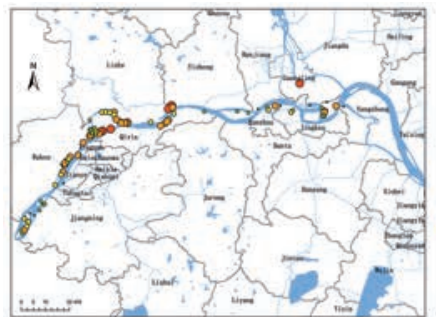

2001

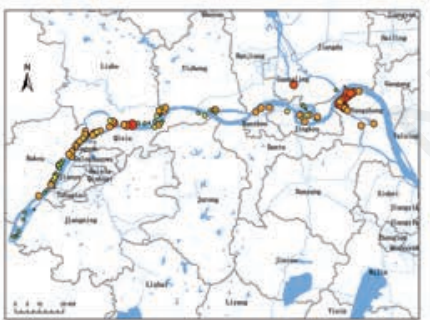

2005

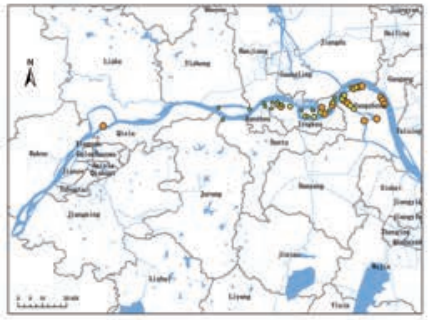

2009

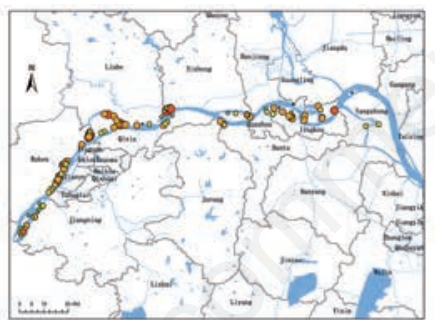

2002

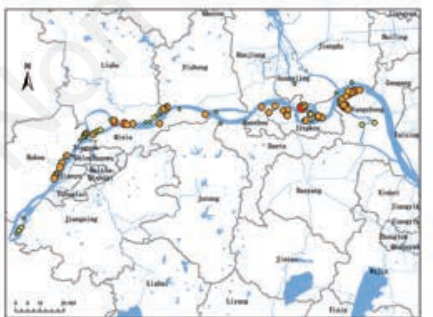

2006

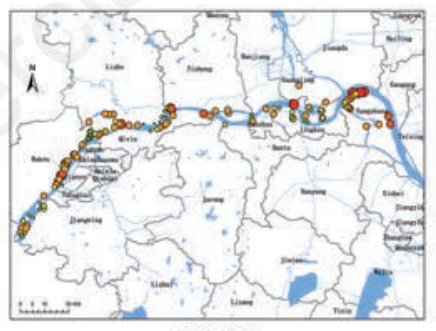

2003

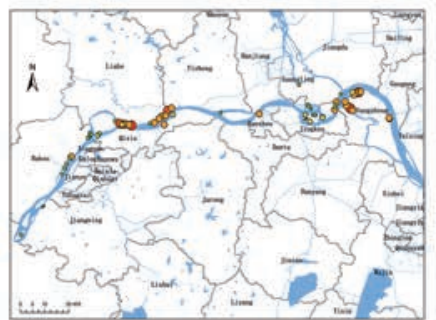

2007

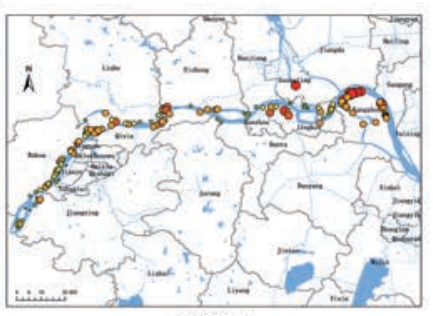

2004

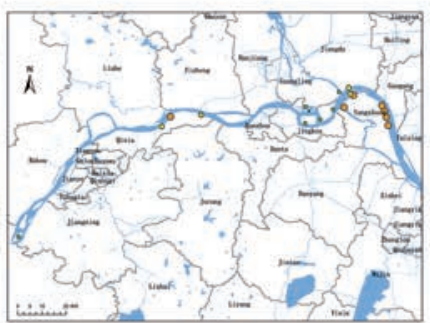

2008

Figure 3. Densities of infected snails along Yangtze River in Jiangsu Province (China), 2001-2009. Note the ongoing, continuous disappearance of infected snail habitats over the period 2001-2009. 
The total snail-infested areas increased significantly in the first 5 years (before the change took place), reaching a peak in 2005 before turning into a consistent, downward trend. Although, there were fluctuations, the overall trend was generally downward.

The snail densities found along Yangtze River are displayed as circles of different colours and sizes on the map in Figure 2. Green colour and small size indicate low densities, red and large size high densities with yellow and amber representing intermediate values (Figure 2). The average snail density declined from 2.0512 snails $/ 0.1 \mathrm{~m}^{2}$ in 2001 to 0.3739 snails $/ 0.1 \mathrm{~m}^{2}$ in 2013 (a reduction of $81.8 \%$ ), while the density of infected snails declined from 0.0027 snails $/ 0.1 \mathrm{~m}^{2}$ in 2001 to 0.0006 snails/0.1 $\mathrm{m}^{2}$ in 2009 (Figure 3 ). The chi-square test showed that the snail density in general $\left(\chi^{2}=493.573, \mathrm{P}<0.01\right)$, as well as that of infected snails $\left(\chi^{2}=71.647, \mathrm{P}<0.01\right)$, had declined significantly. The linearby-linear association test also showed a linear downward trend of snail densities, for all snails $\left(\chi^{2}=247.752, \mathrm{P}<0.01\right)$ as well as for those infected $\left(\chi^{2}=20.615, \mathrm{P}<0.01\right)$.

The total area of snail habitats along Yangtze River declined from $57.7 \mathrm{~km}^{2}$ in 2001 to $25.4 \mathrm{~km}^{2}$ in 2013 , while the area harbouring infected snails along Yangtze River was $16.3 \mathrm{~km}^{2}$ in 2001, after which there was a downward trend ending with total elimination of infected snail habitats in 2010 (Figure 4). Although the proportion of snail-infested marshlands in Jiangsu Province made up more than 90\% of all areas, the number of all snail habitats declined from 390 in 2001 to 151 in 2013 (a reduction by $61.3 \%$ ). The number of infected snail habitats in these regions was even more strongly reduced and these habitats disappeared completely by 2010 . The maps also show that the density of infected snail habitats in the marshlands along Yangtze River lingered the longest in the downstream areas of the river.

\section{Spatial autocorrelation}

At the provincial level, global autocorrelation indicated annual, statistically significant spatial clusters of snail density $(\mathrm{P}<0.05)$ during the entire study period with exception of the years 2009 and 2013 (Figure 5 and Table 2). However, as can be seen in the table, local clusters were observed in 2001 and from 2003 to $2007(\mathrm{P}<0.05)$ when investigating the presence and density of infected snails, No infected snails existed after 2009 and the distribution was random in the other years (2002 and 2008-2009).

When investigating local autocorrelation with the $\mathrm{Gi}^{*}$ method, it was found that the snails in the period 2001-2007 were mainly concentrated in Nanjing, Yangzhou and other places along the upper reaches of the Yangtze River, while hotspots began to appear downstream, e.g. in Zhenjiang in 2008, and continued to do so until the end of the study period in 2013 (Figure 6). With regard to infected snails, the hotspots primarily clustered in two regions of Nanjing and Zhenjiang from 2001 to 2003. They did not appear in later years in Nanjing, but remained in Zhenjiang until 2009 (Figure 7). Table 3 shows that high levels of spatial clustering existed during most of the 13-year long study period, both of snails in general and infected snails (however, the latter only up to 2007). The RR of the two snail clusters was 1.19 (Table 3). From 2001 to 2005, the centre of east area was in Jingkou District, Zhenjiang City $\left(\mathrm{E} 119.67^{\circ}, \mathrm{N} 32.26^{\circ}\right)$ with a radius of $14.5 \mathrm{~km}$, which included the entire city of Nanjing as well as three districts of Yangzhou City (Jiangdu, Guangling and Yangzhong) and two districts of Zhenjiang City (Jingkou and Dantu). The other centre existed from 2001 to 2006 and was centred in Yizheng District, Yangzhou City $\left(\mathrm{E} 119.08^{\circ}, \mathrm{N} 32.25^{\circ}\right)$. The radius was $39.9 \mathrm{~km}$, including the districts of Hanjiang and Yizheng in Yangzhou City, the districts of Liuhe, Qixia, Pukou and Jiangning in Nanjing City and the districts of Runzhou, Dantu and Jingkou in Zhenjiang City (Figure 8). Areas at risk due to infected snails covered the whole of Nanjing City

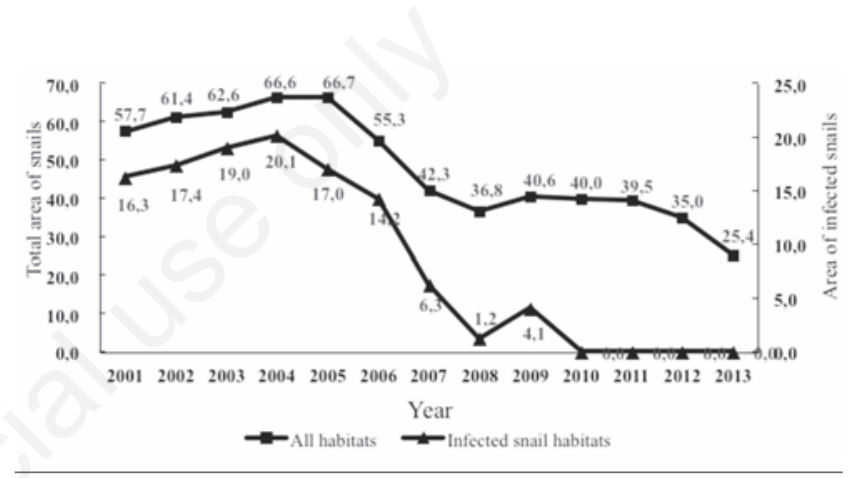

Figure 4. Areas covered by snail habitats along Yangtze River in Jiangsu Province (China), 2001-2013. Measurement in km² $^{2}$.

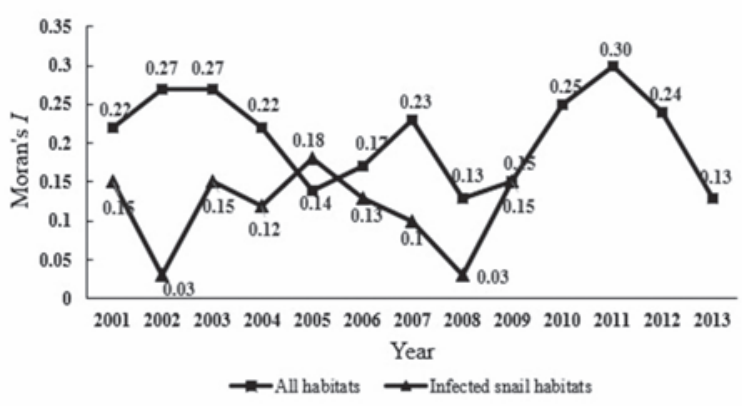

Figure 5. Moran's $I$ applied to snail habitat densities along Yangtze River in Jiangsu Province (China), 2001-2013.

Table 3. Significant clusters found by the SaTScan ${ }^{\text {TM }}$ for snail habitats along Yangtze River in Jiangsu Province (China), $2001-2013$.

\begin{tabular}{lccccccc} 
& No. & Cluster area & & Cluster years & RR \\
& & Latitude $(\mathbf{N})$ & $\begin{array}{c}\text { P } \\
\text { Longitude }(\mathrm{E})\end{array}$ & Radius $(\mathrm{km})$ & & \\
All live snails & 1 & 32.26 & 119.67 & 14.46 & $2001-2005$ & 1.19 & 0 \\
& 2 & 32.25 & 119.08 & 39.85 & $2001-2006$ & 1.19 & 0 \\
Infected snails & 1 & 32.09 & 118.71 & 37.81 & $2002-2007$ & 3.00 & 0 \\
\hline
\end{tabular}

$\mathrm{RR}$, relative risk. 
from 2002 to 2007 with a radius of $37.8 \mathrm{~km}^{2}$ centred on Xiaguan district (Figure 9).

\section{Discussion}

Previous studies have shown beyond doubt that flooding by the Yangtze River and other connected hydrological features are the main reasons for the spread of snails in the marshlands lining the river (Zhou et al., 2002). This makes it clear that an effective way to prevent the transmission of schistosomiasis would be to control the number of snails in these areas, which are frequented by both humans and domestic animals. Although the completion of the Three Gorges Dam has contributed to lower snail counts in general, since the water levels have dropped and flooding has been avoided (Li et al., 2013; Seto et al., 2008; Zhu et al., 2008), the chi-square and linear-by-linear association tests demonstrate that the change of control strategy in 2004 produced statistically verified improved results with respect to the snail numbers that have continued to diminish towards the end of the study period and beyond. This piece of information fills the long-standing gap of understanding how various control approaches work. We conclude thus that the Jiangsu Department of Schistosomiasis, thanks to its scientific planning and snail control strategy, has succeeded in controlling the intermediate snail host and thus the spread of schistosomiasis. It should be noted, however, that although all types of snail habitat have had a downward trend, only the marshlands data were used for the analysis presented here since this type of area dominates completely in

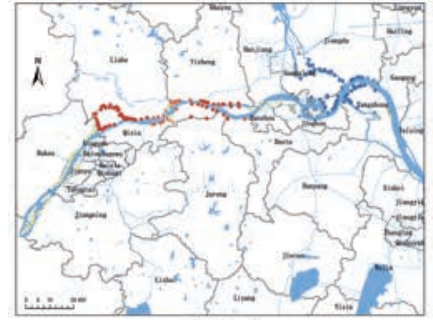

2001

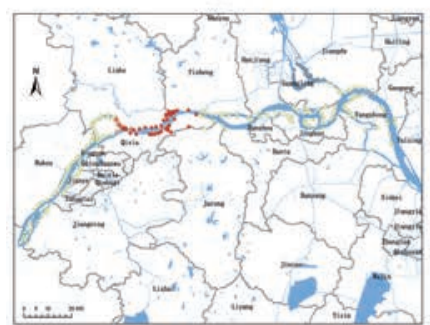

2005

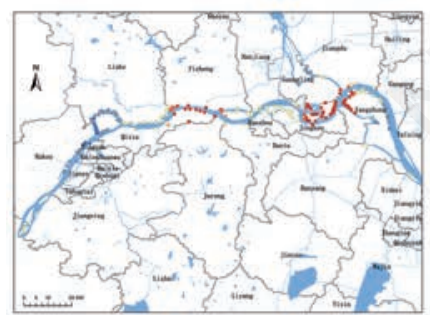

2009

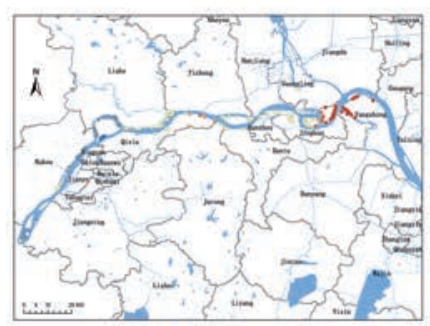

2013

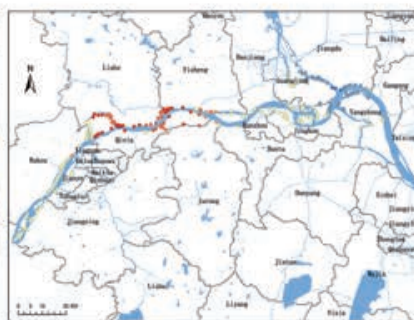

2002

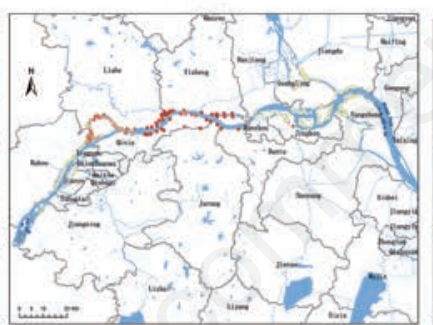

2006

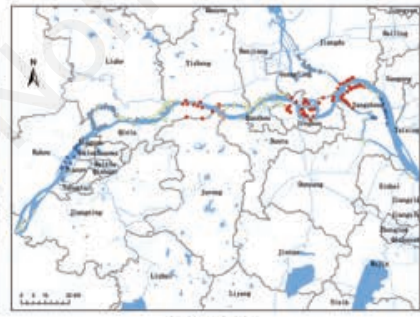

2010

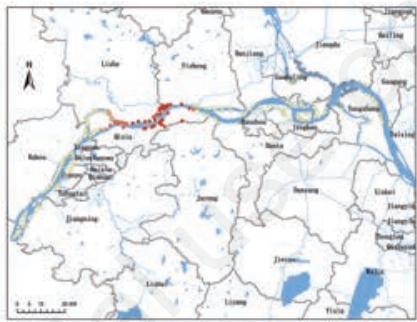

2003

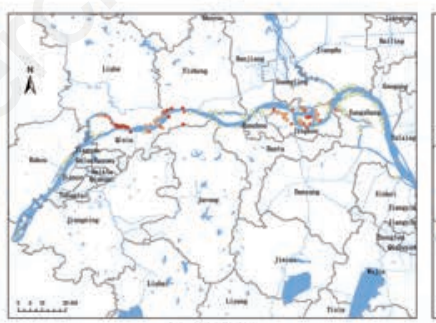

2007

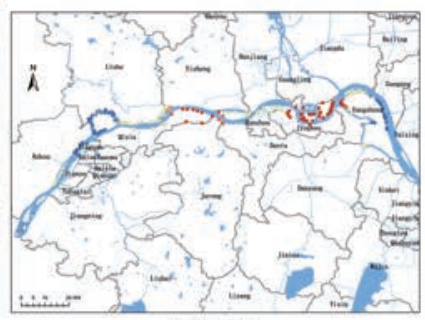

2011

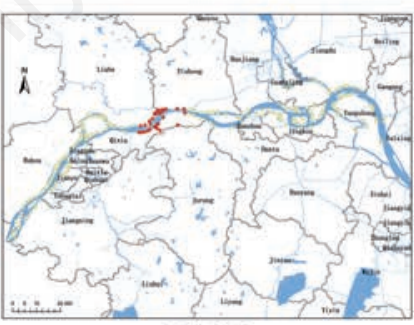

2004

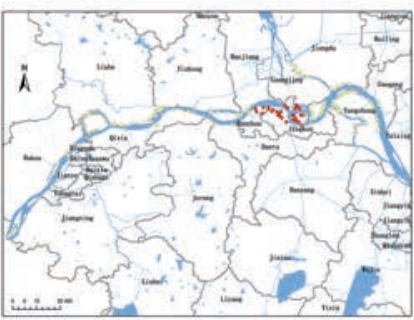

2008

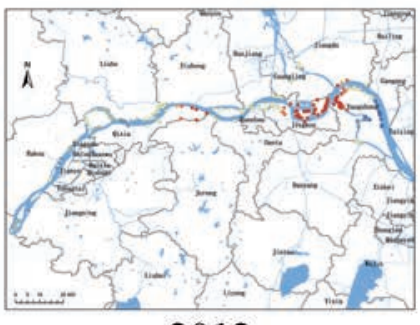

2012

GIZScore

- Cold Spot - $99 \%$ Confidence

- Cold Spot - $95 \%$ Confidence

- Cold Spot - $90 \%$ Confidence

- Not Significant

- Hot Spot - $90 \%$ Confidence

- Hot Spot - $95 \%$ Confidence

- Hot Spot - $99 \%$ confidence

Figure 6. General distribution of snail habitats along Yangtze River in Jiangsu Province, (China) 2001-2013. 
Jiangsu province (at least $90 \%$ of all snail-infested areas in the province).

Reflecting the degree of autocorrelation in the region, global Morans'I provided essential information on the spatial pattern of the snail distribution in the entire study area, and the $\mathrm{Gi}^{*}$ index revealed the relevance of this property for each and adjacent spatial units (Sokal and Oden, 1978). Cluster formation at the provincial level, seen in most of the study years, indicated that some area(s) may include undetected high-density snail habitats. However, the disappearance of clusters of infected snails in the years before they were eliminated, and the declining cluster trend of snails in general in recent years, support the goal of eliminating schistosomiasis in China in the next decade (Tambo et al., 2014). The declining trend of hotspots and the change of local clusters from upstream to midstream of Yangtze river, as indicated by the Gi* index, are signs of the difference between snail control activities in different cities. This important finding indicates that some places located midstream of the Yangtze River in Jiangsu province need to pay more attention to the schistosomiasis problem and institute better snail control. The noted move of local clusters from low latitudes to high latitudes is of interest and requires further study to find out whether it is associated with environmental change as suggested by Zhou et al. (2008).

Two clusters of snail presence were found at the upstream and midstream of the Yangtze River in Jiangsu Province using spatio-tempo- ral scanning. Time-wise, these clusters were almost identical to those that occurred in 2001-2006 and 2001-2005. Unlike the Gi* index, no clusters were discovered by SaTScan after 2006, while the Gi* index indicated continued existence of hotspots. The reason may be related to the different principles used by these two statistical approaches. Local spatial autocorrelation uses the spatial properties of one unit for the estimation of adjacent units indicating hotspots and cold spots by the statistically significance of property difference (Flahaut et al., 2003; Viladomat et al., 2014). The hotspots of infected snails showed statistical significance in the midstream location. The absence of clusters in this area by SaTScan method could be due to the fact that SaTScan calculates the relative likelihood ratio with non-clustering area under different radii by Monte-Carlo iterative simulation (Chong et al., 2013; Luo, 2013; Sherman et al., 2014). The snail density clearly decreased significantly and it was eventually hard to find a specific area showing a cluster phenomenon. Although differences between the two methods were recorded, the bottom line is that the integrated control strategy instituted in 2004 in Jiangsu province has had a good effect.

Apart from incurring at least some loss of information by the transfer of density data from actual measurement to numeration, the main limitation of this study is that it was only based on two variables, i.e. space and time. The effect of the many different environmental factors, which influence the spread and growth of the snail, could not be

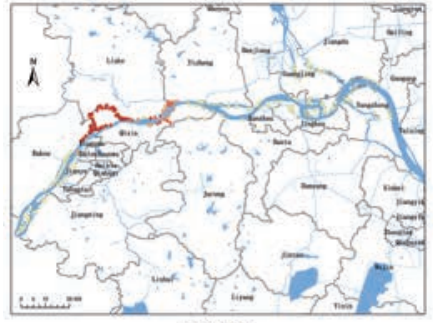

2001

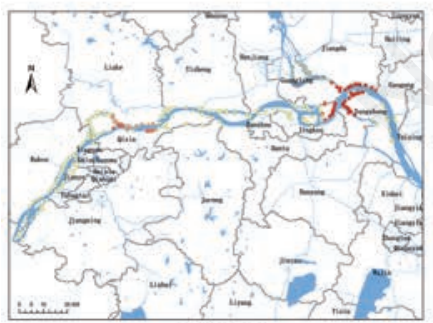

2005

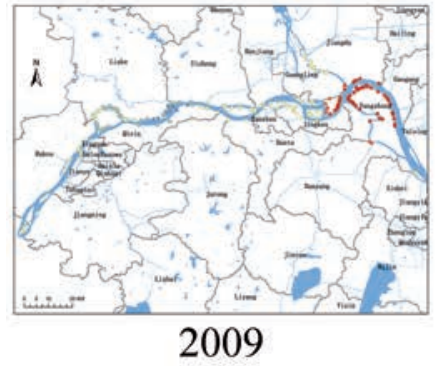

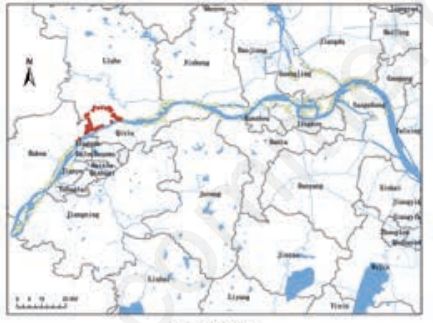

2002

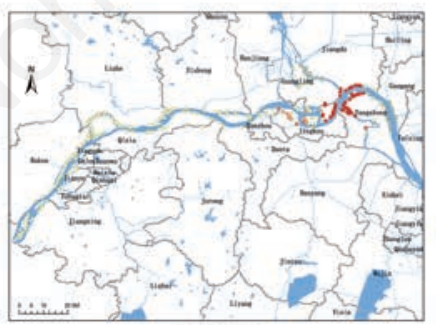

2006

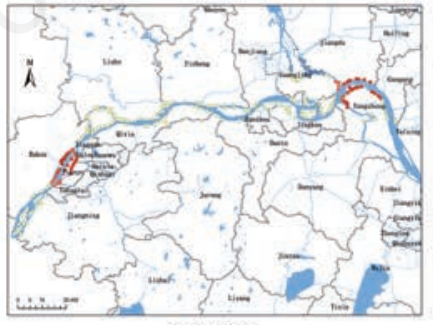

2003

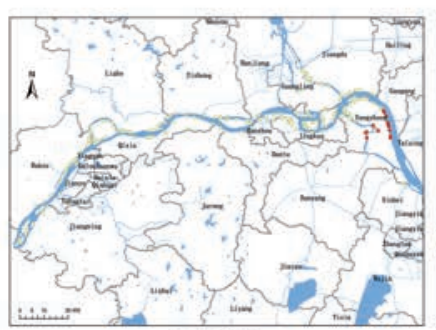

2007

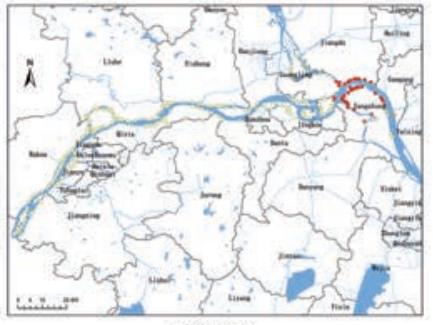

2004

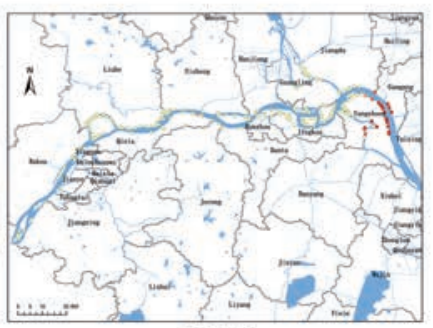

2008

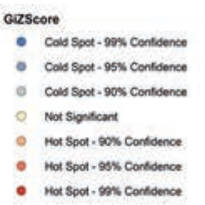

Figure 7. Distribution of infected snail habitats along Yangtze River in Jiangsu Province, (China) 2001-2013. 


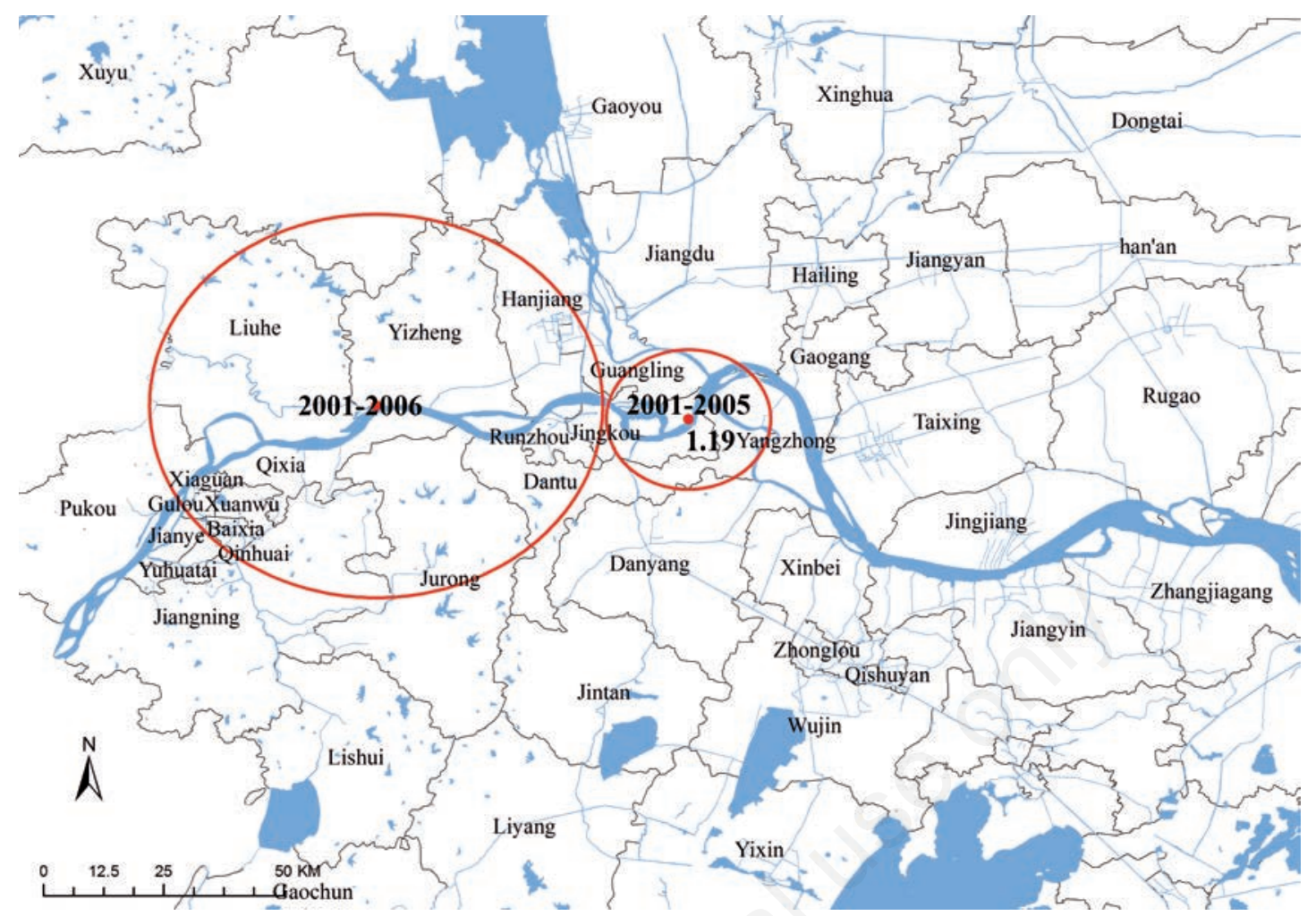

Figure 8. Spatio-temporal centres of snail habitats along Yangtze River in Jiangsu Province, (China) 2001-2013. The biggest cluster had a radius of $39.9 \mathrm{~km}$ and existed from 2001 to 2006 with its centre in Yizheng district, Yangzhou City, while the smaller one had a radius of $14.5 \mathrm{~km}$ and existed from 2001 to 2005 with its centre in Jingkou District, Zhenjiang City.

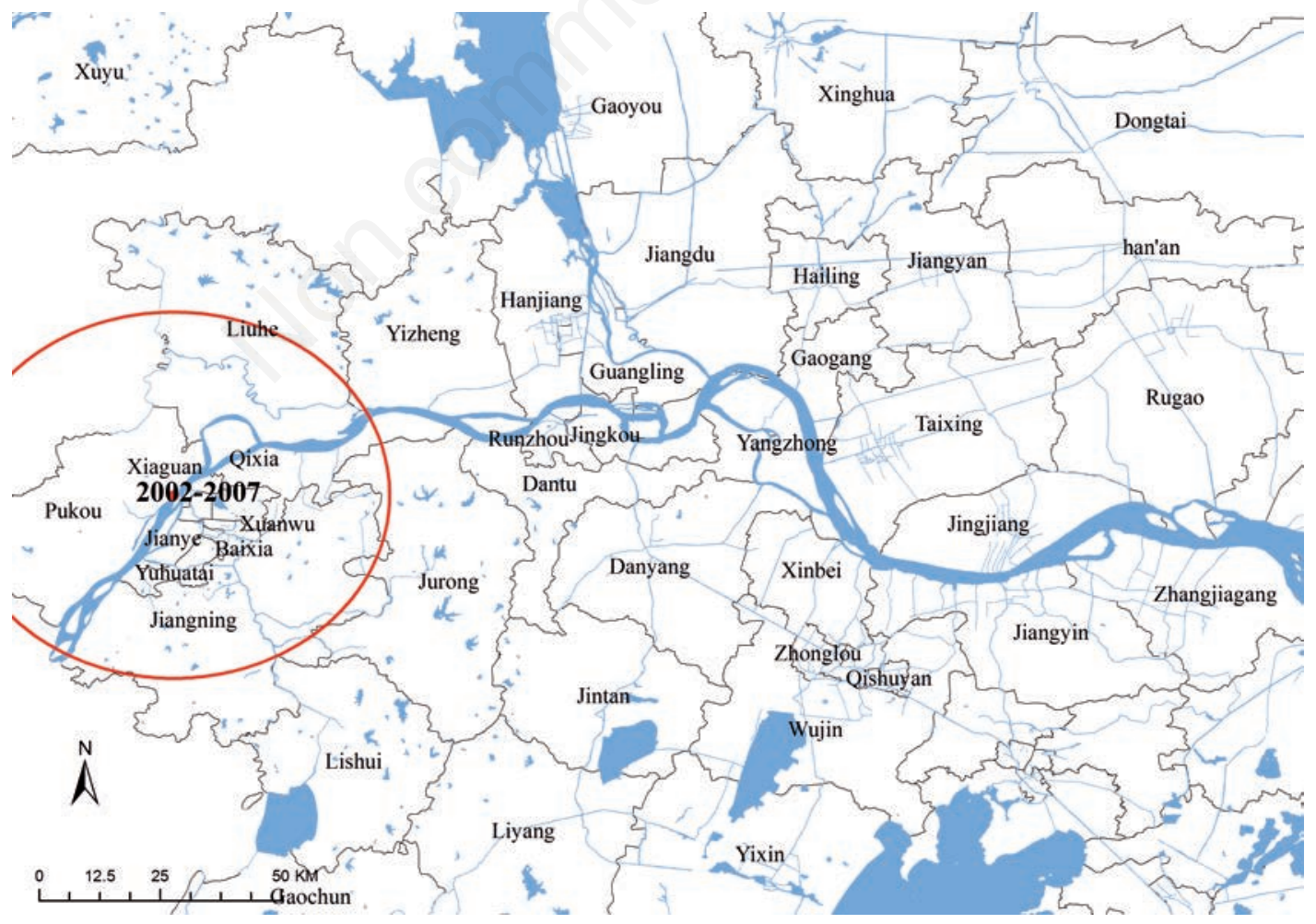

Figure 9. Spatio-temporal centre of infected snails along Yangtze River in Jiangsu Province, (China) 2001-2013. The total area at risk covered the whole Nanjing City from 2002 to 2007 with a radius of $37.8 \mathrm{~km}$ centred on Xiaguan District. 
taken into account, partly since we focused on the marchlands only. Indeed, the inclusion of such factors and application of Bayesian spatio-temporal modelling would be the next step for a more detailed analysis of which factors and changes have strongest effect.

\section{Conclusions}

Statistically significant differences among the years of the study period were observed after the institution of an integrated strategy, even if the effect of the spread and growth of the intermediate $S$. japonicum host snails are difficult to pin down. By using a long-time evaluation, a clear reference for a sustained, downward trend was found with respect to the total number of snails in the endemic areas studied, including the elimination of infected snails. This finding supports the need for the implementation of an integrated snail control strategy to reach elimination of schistosomiasis in the next 5-10 years.

\section{References}

Agresti A, 1991. Categorical data analysis. John Wiley \& Sons, New York, NY, USA.

Chen X, Jiang Q, Wang L, Zhao G, Zhao Q, Gu Y, Wei J, Hao Y, 2002. Schistosomiasis situation in the People's Republic of China in 2001. Chin J Schisto 14:241-3.

Chong S, Nelson M, Byun R, Harris L, Eastwood J, Jalaludin B, 2013. Geospatial analyses to identify clusters of adverse antenatal factors for targeted interventions. Int J Health Geogr 12:46.

Coleman M, Coleman M, Mabuza AM, Kok G, Coetzee M, Durrheim DN, 2009. Using the SaTScan method to detect local malaria clusters for guiding malaria control programmes. Malaria J 8:1-6.

Collins C, Xu J, Tang S, 2012. Schistosomiasis control and the health system in P.R. China. Infect Dis Poverty 1:8.

Flahaut B, Mouchart M, San Martin E, Thomas I, 2003. The local spatial autocorrelation and the kernel method for identifying black zones. A comparative approach. Accident Anal Prev 35:991-1004.

Hong QB, Yang K, Huang YX, Sun LP, Yang GJ, Gao Y, Zhang LH, Zhou M, Steinmann P, Liang YS, 2011. Effectiveness of a comprehensive schistosomiasis japonica control program in Jiangsu province, China, from 2005 to 2008. Acta Trop 120(Suppl.1):151-7.

Lei Z, Zheng H, Zhang L, Zhu R, Xu Z, Xu J, Fu Q, Wang Q, Li S, Zhou $\mathrm{X}, 2014$. Endemic status of schistosomiasis in People's Republic of China in 2013. Chin J Schisto 26:591-7.

Li W, Hang DR, You BR, Chen XJ, Chen XJ, Yang K, Liang YS, 2013. Effect of environmental change in marshland after implementation of Three Gorges Reservoir Project on schistosomiasis in Jiangsu Province. Chin J Schisto 25:576-580, 584.

Liang YS, Huang YX, Hong QB, Yang K, Sun LP, Dai JR, Yang GJ, Yu CX, Tian ZX, Ge J, Wu HH, Gao Q, 2012. Novel strategies and technologies to achieve the transmission control of schistosomiasis in Jiangsu Province. Chin J Schisto 24:119-22.

Luo L, 2013. Impact of spatial aggregation error on the spatial scan analysis: a case study of colorectal cancer. Geospat Health 8:22-35.

Ord JK, Getis A, 1995. Local spatial autocorrelation statistics: distributional issues and an application. Geogr Anal 27:286-306.

Seto EY, Wu W, Liu H-Y, Chen H-G, Hubbard A, Holt A, Davis GM, 2008. Impact of changing water levels and weather on Oncomelania hupensis hupensis populations, the snail host of Schistosoma japonicum, downstream of the Three Gorges Dam. Ecohealth 5:149-58.

Sherman RL, Henry KA, Tannenbaum SL, Feaster DJ, Kobetz E, Lee DJ, 2014. Applying spatial analysis tools in public health: an example using SaTScan to detect geographic targets for colorectal cancer screening interventions. Prev Chronic Dis 11:41.

Sokal RR, Oden NL, 1978. Spatial autocorrelation in biology: 1. Methodology. Biol J Linn Soc 10:199-228.

Sun LP, Liang YS, Wu HH, Tian ZX, Dai JR, Yang K, Hong QB, Zhou XN, Yang GJ, 2011. A Google Earth-based surveillance system for schistosomiasis japonica implemented in the lower reaches of the Yangtze River, China. Parasite Vector 4:223.

Tambo E, Ai L, Zhou X, Chen JH, Hu W, Bergquist R, Guo JG, Utzinger J, Tanner M, Zhou XN, 2014. Surveillance-response systems: the key to elimination of tropical diseases. Infect Dis Poverty 3:17.

Truong LT, Somenahalli SV, 2011. Using GIS to identify pedestrian-vehicle crash hot spots and unsafe bus stops. J Publ Transporta 14:6.

Viladomat J, Mazumder R, McInturff A, McCauley DJ, Hastie T, 2014. Assessing the significance of global and local correlations under spatial autocorrelation: a nonparametric approach. Biometrics 70:409-18.

Wang LD, Chen HG, Guo JG, Zeng XJ, Hong XL, Xiong JJ, Wu XH, Wang XH, Wang LY, Xia G, Hao Y, Chin DP, Zhou XN, 2009. A strategy to control transmission of Schistosoma japonicum in China. New Engl J Med 360:121-8.

Ward MP, Carpenter TE, 2000. Analysis of time-space clustering in veterinary epidemiology. Prev Vet Med 43:225-37.

Wilke T, Davis GM, Cui-E C, Xiao-Nung Z, Peng ZX, Yi Z, Spolsky CM, 2000. Oncomelania hupensis (Gastropoda: Rissooidea) in eastern China: molecular phylogeny, population structure, and ecology. Acta Trop 77:215-27.

Wu X-H, Zhang S-Q, Xu X-J, Huang Y-X, Steinmann P, Utzinger J, Wang T-P, Xu J, Zheng J, Zhou X-N, 2008. Effect of floods on the transmission of schistosomiasis in the Yangtze River valley, People's Republic of China. Parasitol Int 57:271-6.

Yang G, Vounatsou P, Zhou X, Tanner M, Utzinger J, 2005. A potential impact of climate change and water resource development on the transmission of Schistosoma japonicum in China. Parassitologia 47:127-34.

Yang G-J, Zhou X-N, Sun L-P, Wu F, Zhong B, Qiu D-C, Utzinger J, Bradshaw CJ, 2011. Compensatory density feedback of Oncomelania hupensis populations in two different environmental settings in China. Parasite Vector 4:133.

Yang K, Sun LP, Huang YX, Yang GJ, Wu F, Hang DR, Li W, Zhang JF, Liang YS, Zhou XN, 2012a. A real-time platform for monitoring schistosomiasis transmission supported by Google Earth and a web-based geographical information system. Geospat Health 6:195203.

Yang K, Wang XH, Yang GJ, Wu XH, Qi YL, Li HJ, Zhou XN, 2008. An integrated approach to identify distribution of Oncomelania hupensis, the intermediate host of Schistosoma japonicum, in a mountainous region in China. Int J Parasitol 38:1007-16.

Yang K, Yang GJ, Hong QB, Huang YX, Sun LP, Gao Y, Gao Y, Zhang LH, Yang JB, Zhu HR, Liang YS, 2012b. Surveillance of schistosomiasis in Jiangsu Province, China, 2005-2010. Chin J Schisto 24:527-32.

Yaniv SS, Levy A, Wiznitzer A, Holcberg G, Mazor M, Sheiner E, 2011. A significant linear association exists between advanced maternal age and adverse perinatal outcome. Arch Gynecol Obstet 283:755-9.

Zhang Z, Ong S, Peng W, Zhou Y, Zhuang J, Zhao G, Jiang Q, 2008. A model for the prediction of Oncomelania hupensis in the lake and marshland regions, China. Parasitol Int 57:121-31. 
Zhou X, Dandan L, Huiming Y, Honggen C, Leping S, Guojing Y, Qingbiao H, Brown L, Malone J, 2002. Use of landsat TM satellite surveillance data to measure the impact of the 1998 flood on snail intermediate host dispersal in the lower Yangtze River Basin. Acta Trop 82:199-205.

Zhou XN, Guo JG, Wu XH, Jiang QW, Zheng J, Dang H, Wang XH, Xu J, Zhu HQ, Wu GL, Li YS, Xu XJ, Chen HG, Wang TP, Zhu YC, Qiu DC, Dong XQ, Zhao GM, Zhang SJ, Zhao NQ, Xia G, Wang LY, Zhang SQ, Lin DD, Chen MG, Hao Y, 2007. Epidemiology of schistosomiasis in the People's Republic of China, 2004. Emerg Infect Dis 13:1470-6.
Zhou XN, Yang GJ, Yang K, Wang XH, Hong QB, Sun LP, Malone JB, Kristensen TK, Bergquist NR, Utzinger J, 2008. Potential impact of climate change on schistosomiasis transmission in China. Am J Trop Med Hyg 78:188-94.

Zhou Y, Zheng H, Chen Y, Zhang L, Wang K, Guo J, Huang Z, Zhang B, Huang W, Jin K, 2009. The Schistosoma japonicum genome reveals features of host-parasite interplay. Nature 460:345-51.

Zhu HM, Xiang S, Yang K, Wu XH, Zhou XN, 2008. Three Gorges Dam and its impact on the potential transmission of schistosomiasis in regions along the Yangtze River. Ecohealth 5:137-48. 